INVESTIGACIÓN/RESEARCH

Recibido: 07/12/2014---Aceptado: 17/12/2014---Publicado: 15/12/2014

\title{
UN RECORRIDO POR CATEGORÍAS Y REPRESENTACIONES SOBRE JUVENTUD EN LAS CIENCIAS SOCIALES
}

María Gabriela Palazzo . CONICET, Universidad Nacional de Tucumán, Argentina. gabupalazzo@gmail.com

\section{RESUMEN}

Este trabajo propone un recorrido teórico sobre distintas formas de estudiar las juventudes en nuestro tiempo, atendiendo a determinadas categorías y representaciones desde las que se han abordado tales investigaciones. Estas constituyen hechos discursivos relevantes por su incidencia en la construcción del conocimiento tanto académico como del saber de sentido común.

A partir de una selección de líneas y autores que proponen formas de comprender la cuestión juvenil desde distintos campos del conocimiento en las Ciencias Sociales, se revisan nociones como las de identidad, generación, cultura, subcultura y cibercultura juveniles.

Asimismo, el trabajo indaga en la operatividad de categorías tales como las de tribus urbanas y nativos/inmigrantes digitales en tanto formas de definir a los y las jóvenes en la actualidad según sus prácticas, especialmente en el Ciberespacio.

Finalmente, se hace referencia a resultados de mi propia investigación desde la perspectiva de los Estudios del Discurso

\footnotetext{
1 María Gabriela Palazzo. Doctora en Letras, Universidad Nacional de Tucumán (Argentina). Investigadora Asistente del CONICET. Profesora Adjunta en la Facultad de Filosofía y Letras, UNT. Investiga temas de juventud desde la perspectiva de los Estudios del Discurso.
} 


\title{
PALABRAS CLAVE
}

Recorrido-categorías-representaciones-juventud-Ciencias Sociales

\section{AN ITINERARY ACROSS CATEGORIES AND REPRESENTATIONS ON YOUTH IN SOCIAL SCIENCES}

\begin{abstract}
This work proposes a theoretical itinerary on various forms of studying youths in our times, considering certain categories and representations from which those investigations have been approached. These studies constitute relevant discursive facts given their impact in knowledge building in both academic and common sense knowledge.

From a selection of lines and authors that propose ways of understanding the issue of youth from various fields of knowledge within Social Sciences, notions such as identity, generation, culture, subculture and youth cyberculture are revised.

In addition, this work analyses the operativeness of categories such us urban tribes and digital natives/immigrants as ways of defining the young nowadays according to their practices, especially in the Cyberspace.

Finally, referring to results of my own investigation is done from the perspective of Discourse Studies
\end{abstract}

\section{KEY WORDS}

Youth - Categories - Representations - Social Sciences.

\section{INTRODUCCIÓN}

Los jóvenes tienen fuertes pasiones, y suelen satisfacerlas de manera indiscriminada. De los deseos corporales, el sexual es el que más los arrebata y en el que evidencian la mayor falta de autocontrol. Son mudables y volubles en sus deseos, que mientras duran son violentos, pero 
pasan rápidamente. Su vida no transcurre en el recuerdo sino en la expectativa, ya que la expectativa apunta al futuro, el recuerdo al pasado y los jóvenes tienen un largo futuro delante de ellos y un breve pasado detrás.

\section{Aristóteles, Retórica}

¿Quién no ha nombrado a la juventud? La propia, la pasada, la futura; buscándola, imaginándola, escribiéndole o cantándole, o procurando entenderla en su variedad, complejidad y también, intentando explicarla en este mundo azorado de cambios y contradicciones.

El siglo XXI habla mucho de la juventud. En singular o en plural, en masculino y femenino, en presente, en pasado o en futuro. $Y$ presumo que esto se debe a que las juventudes, las y los jóvenes son discurso, son prácticas, son protagonistas de la historia, de las historias, una constante transversal a todos los discursos y procesos sociales. Desde los "dominios borrosos" del sentido común o la intuición hasta los "dominios teóricos" de los textos especializados -por usar la lúcida metáfora de Mignolo- mediante categorías que, por explicativas, pueden volverse infranqueables. En nuestro presente, estudiar las juventudes se ha vuelto una tarea casi indispensable para comprender las dinámicas sociales.

En el transcurso del siglo XXI los jóvenes han adquirido una nueva visibilidad en relación con distintos ámbitos sociales y escenarios de participación civil, política, discursiva, etc., o bien como sujetos vulnerables en contextos de crisis.

Los discursos sociales, en especial los académicos, fueron construyendo, reproduciendo e incluso naturalizando determinados rasgos que "ubican" a los jóvenes en categorías clasificatorias, descriptivas o interpretativas.

$\mathrm{Si}$ el discurso supone un posicionamiento respecto de la realidad: ¿cómo se habla sobre jóvenes en la investigación social? y, derivado de ello ¿cómo se ha nombrado y se nombra a las juventudes desde los campos del conocimiento científico y sociocultural?

Estas preguntas son cuestiones que involucran aristas o variables directamente relacionadas con ubicaciones culturales, ideológicas y también del sentido común de 
las sociedades, lo que, desde una perspectiva cognitiva se denomina la cognición social. Esa relación triádica entre poder/discurso/coginición que estableció Van Dijk para el estudio del discurso ideológico. Porque el conocimiento se construye y difunde a través de mecanismos y carriles que tienen que ver con el poder de las instituciones y medios de comunicación más hegemónicos o bien, privilegiados.

\section{OBJETIVOS}

Los objetivos a los que se orienta esta revisión son: a) retomar formas relevantes de categorización, definición y representación social de los y las jóvenes en el contexto de las Ciencias Sociales que conforman los Estudios sobre Juventudes y b) Contribuir a la construcción de un mapa discursivo que revise las representaciones sociales, definiciones, metáforas y construcciones o formas de imaginar y poner en discurso los lugares sociales juveniles en relación con los nuevos medios, el Ciberespacio y la era digital en el siglo XXI.

Este mapeo es necesario para poder plantear nuevas aproximaciones o poner en discusión las formas y categorías que se han ido estableciendo en estos últimos años en relación con los jóvenes, la cultura y los nuevos medios de comunicación, el ciberespacio y la era digital.

\section{METODOLOGÍA}

La tesis central de la investigación que me ocupa parte de la premisa de que las categorías no son neutras ni esencialistas sino productivas, y por tanto dan cuenta, tal como lo explica Reguillo Cruz (2012, p.25): “de la manera en que diversas sociedades perciben y valoran el mundo $y$, en consecuencia, a ciertos actores sociales". $\mathrm{Y}$ es precisamente a través del discurso -en sus distintas formas- que las representaciones sobre los jóvenes cobran forma y vigor.

En estas páginas, por tratarse de una revisión teórica y no de un estudio de caso, se traza un recorrido por una serie de puntos o mojones que considero relevantes para repasar de qué se habla en la investigación sobre jóvenes, cuando se dice juventud²,

\footnotetext{
2 Este artículo es parte de mi investigación en curso como Investigadora Asistente del Conicet: “Formas de representación de la juventud en discursos sociales y prácticas discursivas juveniles en
} 
considerando los/las investigadores/as que les han dado forma y trascendencia. Igualmente, aludiré a algunos resultados y reflexiones que se fueron suscitando en mi propia tarea de investigación, especialmente en relación con la funcionalidad del Análisis del Discurso en el contexto de los Estudios sobre Juventudes.

De acuerdo con los objetivos propuestos, el trabajo realizado se basa en la recolección y selección de instrumentos teóricos en la bibliografía especializada y en relación con la formación del campo de estudios sobre juventudes relativos a las TICs, nuevos medios, ciberespacio y perspectivas generacionales.

Se realiza entonces un tratamiento teórico de las representaciones discursivas, las discusiones y los posicionamientos de los distintos agentes que construyen esas definiciones, así como de su eventual operatividad.

\section{RESULTADOS}

\subsection{Acerca de las categorizaciones sobre juventud}

Con respecto a las investigaciones acerca de las subjetividades juveniles, Reguillo Cruz advierte que no se puso en contexto, o bien no se superó la dimensión descriptiva de los estudios sobre prácticas del lenguaje y de consumo cultural juveniles.

En coincidencia con esta postura, el sociólogo chileno Duarte Quapper (2011) se manifiesta a favor de investigaciones que superen las categorizaciones totalizantes y universalizadoras, la "rigidez mecanicista con que se ha mirado y se ha hablado de la juventud." con la pretensión de generar conceptos dinámicos y flexibles que se acerquen progresivamente a los sujetos de estudio: las y los jóvenes, las juventudes, las expresiones juveniles, los procesos de juvenilización.

Tucumán" y "Nuevas representaciones y construcciones discursivas sobre juventudes y ciberespacio". 
Esto supone comprender que la emergencia de los sujetos jóvenes como condición de estudio ocurre a través de un proceso dinámico, diferenciado y sin fin (op.cit:p.17 y ss)

-Dinámico, ya que no acontece en un determinado momento -una fecha- o a partir de un cierto hito social -un suceso-, sino que se trata de procesos con ritmos e intensidades diversas según el contexto en que ocurren, las múltiples causas que los generan, los efectos que se van ocasionando y los modos en que los propios jóvenes se movilizan ante su situación social y política.

-Diferenciado, porque no ocurre de igual manera en las distintas clases sociales, en los géneros, las razas y la localización territorial.

-Sin fin, porque, mirando a la historia como proceso de larga duración, nos damos cuenta de que aún se está produciendo este cambio societal. Ese proceso está y seguirá en producción, en cuanto constituye una respuesta a las condiciones que generan en cada época este y otros grupos sociales.

Para ello propone desarrollar ciertas herramientas analíticas que constituyen una triada:

- Los modos de expresión y materialización de este proceso de aparición e instalación de las juventudes en la historia junto a las condiciones de diverso tipo que posibilitaron esa emergencia.

-Las relaciones generacionales.

- Los modos diversos y plurales de ser joven y de producir lo juvenil que se construyen en cada época.

El desarrollo de los trabajos sobre juventudes, especialmente en Latinoamérica, está ofreciendo una variedad de enfoques que se orientan hacia estos aspectos. Los jóvenes se perciben y se estudian como sujetos sociales. Esto podría significar, en 
términos de Reguillo Cruz (2012, p.30) que son sujetos de discurso y agentes sociales, "con capacidad para apropiarse de (y movilizar) los objetos tanto sociales y simbólicos como materiales".

En este sentido, todas las áreas de las Ciencias Sociales están en actividad, produciendo trabajos teóricos, académicos, de campo, etc. que atienden tanto a los discursos como a los procesos, a las prácticas como a los sujetos, a las políticas como a las representaciones sociales. A los viejos y nuevos medios, sus apropiaciones y usos, a las formas de sociabilidad juveniles, las cuestiones de género, jurídicas, filosóficas, políticas, estéticas e ideológicas.

Asimismo, es palpable la voluntad de construir y difundir la complejidad del estado del arte en el campo de los Estudios sobre Juventudes en Argentina, integrando las diferentes perspectivas de análisis y problemáticas, así como las áreas de vacancia (Chaves,2007; Pini et al.,2012; Zaffaroni, 2012; Borobia, 2014).

Me detendré, entonces, en algunas matrices epistemológicas que han servido de sustento a las representaciones sociales y a la generación de categorías sobre juventudes.

\subsection{La identidad juvenil}

Uno de los ejes de investigación en juventudes que fue recobrando vigor en los últimos años es el relacionado con la identidad juvenil, o las identidades juveniles en diferentes contextos y escenarios.

Buckingham, en el volumen colectivo Youth, Identity, and Digital Media publicado en 2008 repasa el concepto de identidad en vinculación con la juventud, advirtiendo que se trata de un término resbaladizo, rasgo que ya se anticipa en la etimología de la palabra (idem ), que implica similariedad y diferencia a la vez.

Por una parte, entonces, advierte que la identidad es interpretada como algo único que nos distingue de los demás: algo que poseemos. Por otra parte, implica la relación con un colectivo más amplio o un grupo social de algún tipo. Aquí, 
identidad se refiere a la identificación con otros a los que suponemos similares a nosotros, al menos en algunos aspectos significativos.

Sin embargo, de acuerdo con la visión de Bauman (apud Buckingham, 2008:p.1) en el marco de un mundo globalizado, que contribuye a la fragmentación e incertidumbre, la identidad se torna cada vez más problemática. Los recursos tradicionales para la formación de identidad ya no son tan sencillos o están disponibles fácilmente. La metáfora de la identidad líquida (fluida), expresa esta condición, casi infinitamente negociable, que se vuelve un problema cuando se ve amenazada o debe ser afirmada explícitamente.

Los modos de ser joven en esta última década transitan, en mayor o menor medida, por este entorno de fluidez; en muchos casos y a través de los más diversos medios, es evidente el deseo de hacer visible el acto de identidad, el gesto de apropiación de recursos culturales para nombrar sus identidades.

Otra construcción que representa las identidades en el cambio de época (Martín Barbero, 2002) es la metáfora inglesa de las mooving roots; se multiplican los referentes y la diversidad cultural existe en los territorios reales y de las redes, desde donde se resiste, enfrenta e interactúa con la globalización.

En este punto, convendría retomar la redefinición del concepto de identidad propuesta por Jenkins (2000), a partir de una dialéctica de identificación; es decir, la identidad como un fluido contingente dentro del proceso social. El conocimiento depende de la clasificación; la identificación especifica lo que las cosas son o no son. De este modo, la identificación social emerge como producto de un proceso de similitudes y diferencias, en momentos internos (autoidentificación o identificación grupal) y externos (clasificaciones) dentro de esta dialéctica.

Por otra parte, los discursos sociales institucionalizados construyen, interpretan o rotulan las identidades juveniles, al mismo tiempo, en el afán de narrar el presente y ponerle un nombre a las cosas, las anticipan o bien, en sus silencios, las ignoran. 
Existe un amplio rango de subdisciplinas y paradigmas intelectuales -psicología del desarrollo, teoría social, interaccionismo simbólico, estudios culturales, etc- que han buscado generar explicaciones definitivas para la cuestión de la identidad. Retomaré, a continuación, los puntos y autores mencionados en Buckingham (op.cit.) ya que conforman una síntesis sólida y clara del tema.

\subsubsection{La psicología de la adolescencia}

A principios del siglo XX, Stanley Hall introduce la noción de adolescencia como periodo de storm and stress, caracterizada por conflictos intergeneracionales, cambios de humor y comportamientos riesgosos, desde una mirada psico-biologicista de los sujetos. Desde esta perspectiva, la cuestión adolescente deriva inexorablemente hacia aspectos negativos de la conducta: drogas, delincuencia, depresión y desviación sexual.

Por otra parte, otro referente clásico del tema es Erik Erikson, heredero y continuador de la teoría de Piaget sobre las "ages and stages"(edades y etapas) en la adultez y vejez. Erikson ve a la adolescencia como un periodo crítico de formación de identidad, donde los individuos vencen la incertidumbre, se vuelven más autoconscientes de sus fortalezas y debilidades y más seguros con sus propias cualidades únicas. Para avanzar, deben atravesar una crisis sobre valores, ideales, ocupaciones futuras e identidad sexual. El adolescente debe resolver conflictos para pasar al siguiente nivel. . Por tanto, el conflicto en la adolescencia se establece entre la identidad y la "confusión de rol".

Resolverlos supone encontrar un rol más o menos establecido en la vida, lo que resulta en la formación de una "virtud" (fuerza psicológica). En esto consiste, a grandes rasgos, la adaptación, cuando los adolescentes arriban a un sentido coherente e integrado de su identidad como algo que persiste en el tiempo. La identidad, en este contexto, se desarrolla individualmente, pero debe ser reconocida y confirmada por otros.

Posteriormente, Marcia (1980) hace foco en el concepto de "crisis de identidad", periodo en el que la persona joven debe considerar las opciones potenciales de vida. Marcia identifica cuatro estados en este proceso: exclusión (se ha evitado la crisis por 
seguir las expectativas de otros), difusión (la persona ha renunciado al intento de hacer el compromiso necesario), moratoria (el sujeto está aun en la crisis, probando distintas alternativas) y triunfo (una vez atravesada la crisis, cuando se realizan elecciones claras sobre quién se quiere ser), según se destaca en Buckingham (op.cit).

Erikson y sus seguidores, aclara Buckingham, afirman que las etapas identificadas son universales, aunque se podría argumentar que la "adolescencia" como tal no existe en periodos históricos más tempranos o en otras culturas. Como muchas de las teorías del desarrollo, este enfoque resulta, finalmente, muy normativo. Aquí la adolescencia es vista en primer lugar como un estado de transición, una cuestión de "futuro", no de "presente".

Esta forma de percibir a los sujetos jóvenes es la que prevaleció en mi estudio sobre representaciones sociales en la prensa y en el discurso social en Tucumán a comienzos del siglo XXI: una juventud que "está siendo" el futuro, pero no es el presente y se confronta constantemente con la nostalgia del pasado. Desviada en sus conductas públicas e "integrada" en el campo de los deportes o de los casos individuales de superación personal.

Sin embargo, el concepto de 'moratoria psicosocial' -periodo de "time out" en el que los jóvenes pueden experimentar con diferentes identidades potenciales e involucrarse en diversos tipos de riesgos- , ha resultado operativo para interpretar las relaciones entre jóvenes y medios digitales, por ejemplo.

Esto puede rastrearse en las investigaciones sobre las variantes en la construcción y representación de las identidades culturales, sexuales o de género, discursivas, ideológicas, etc, o bien en espacios digitales como las redes sociales o blogs y páginas web.

Duarte (op.cit.) advierte que el modo de lectura de la identidad juvenil ha pasado de estar centrado en un individuo al que se definía por su pertenencia a tal o cual familia, de la que heredaba su condición de identidad primordial y excluyente (que era la identidad de clase) hacia identidades que se autorefieren en la actualidad a partir de las producciones (creación-recreación) que las y los jóvenes realizan en 
forma personal o colectivamente. Esto supone leer las emergencias de identidades juveniles como identidades expropiadas a identidades propias.

\subsection{La juventud como riesgo}

La Sociología de la Juventud comparte con la psicología la preocupación por estudiar la socialización juvenil en su preparación gradual para desempeñar roles en la vida adulta. Buckingham destaca que las corrientes tradicionales estudian la construcción de la juventud como riesgo o problema social, en contextos de marginación o de grupos sociales subordinados. Los sociólogos relacionan estas problemáticas no con cuestiones "hormonales" sino con la pobreza y la desigualdad. El interés se centra más bien en las incertidumbres sociales que enfrentan los jóvenes, como ser el paso desde la casa paterna al mercado laboral (Griffin, 1993). Su naturaleza variará significativamente acorde con el contexto social (clase, género y etnicidad).

Asimismo, sostiene, se podría argumentar que hoy en día la juventud se va definiendo a través de operaciones del mercado comercial cuyas representaciones en categorías más concretas comenzaron con los teenagers (en los 50) y siguieron con los "tweens", "adultescentes" "middle youth", "kidults". La invención y el uso de una categoría como "Generación X" y las subsiguientes mutaciones reflejan la complejidad e importancia de las distinciones basadas en la edad en la cultura contemporánea del consumo. Esto demuestra en qué grado la juventud es una construcción más que un estado universal de ser.

\subsection{Las juventudes como subculturas}

Los Estudios Culturales han cuestionado la visión de las expresiones juveniles como sólo funcionales a la futura socialización como adultos; priorizaron entonces el estudio sobre usos y apropiaciones juveniles de los productos culturales para sus propios fines. De allí las categorizaciones operativas de los grupos juveniles en torno al concepto de subculturas: éstas son percibidas por la sociedad como una amenaza al sistema (resistentes y subversivas). A partir de estas indagaciones se deriva el estudio más incipiente de los estilos de vida temporales.

Con respecto a las culturas juveniles, y también a la problemática generacional en la evolución de las culturas democráticas, Feixa (2013:p.18 y ss.) destaca una serie de tendencias de cambio de la cibercultura juvenil europea: juvenilización (la cultura 
juvenil es la más prestigiosa), aculturación (la cultura juvenil está culturizando territorios q no se veían como ámbito cultural), comercialización, prosumerización (los jóvenes son empresarios de su propio estilo de vida), individualización (subjetivización, toma prestado el bricollage); fragmentación, la glocalización, transculturalismo, digitalización (tendencia a ser más expertos en el área digital).En este escenario, el antropólogo advierte que la cultura juvenil es una caja de resonancia de los conflictos y de los cambios.

En cuanto a las categorías de representación de las culturas juveniles actuales, el investigador catalán propone tres modelos, coexistentes y en conflicto: el modelo Tarzán (que son las que derivan de una forma de educación del ciudadano a través del consumo y la educación); en segundo lugar, las culturas juveniles pueden ser vistas como una forma de prolongar la adolescencia, a lo que llama la Juventud Peter Pan. Por último el modelo del Replicante es el joven androide como adaptación. En cualquier caso, sostiene que los jóvenes participantes de cada forma cultural se enfrentan a las culturas dominantes. (Feixa, op.cit, p.16)

\subsection{Neotribalidades juveniles}

La metáfora más conocida y difundida en el campo de los estudios sociológicos y culturales sobre la vida cotidiana ha sido la de tribus urbanas (Maffesoli, 1990), que se basa en considerar que, en las sociedades urbanas contemporáneas, los sujetos no encuentran su identidad, por lo que se conforman neotribalidades en respuesta a esa ausencia. Tribus que son cambiantes, caracterizadas por su emocionalidad, subterraneidad, fisicalidad de la experiencia y nuevas formas de sociabilidad.

Una de las principales críticas a este concepto como forma de adscribir culturalmente a los jóvenes fue desarrollada por Reguillo Cruz en una entrevista de 2011, donde la investigadora cuestiona la categoría por ignorar las desigualdades de clase y por su primitivismo definitorio :

La noción de tribus, de gran efecto mediático, tiene dos problemas fundamentales: elude o no atiende la cuestión vital de las diferencias y desigualdades de clase y por otro lado, tiende a imprimir un sentido primitivo, arcaico en la configuración de las identidades juveniles. Asumiendo esta 
aclaración, es difícil generalizar cuál o cuáles serían las adscripciones o identidades juveniles más populares, ya que los distintos modos, banderas, reivindicaciones entre estas identidades, vuelve muy difícil señalar con precisión a las más 'populares' (Reguillo Cruz, 2011, s/p.)

Quizás convenga recordar que la relación directa entre la noción de tribus y el concepto de juventud no existe en el texto de Maffesoli, sino que los estudios sobre jóvenes, los medios masivos que los divulgaron y los discursos cotidianos que reproducen a los discursos de los medios, la han instalado Esta construcción discursiva se fue naturalizando e instalándose como identificación de las diferentes modas, prácticas, consumos, estéticas y estilos de vida, así como con sus respectivas denominaciones o rotulaciones (punks, floggers, emos, góticos, rappers, cumbieros, skaters, hippies, rollingas, etc.)

Reguillo Cruz propone, como contrapartida, otra construcción figurativa del lenguaje para interpretar la irrupción de los jóvenes en los contextos civilizados, que es la de los jóvenes como nuevos bárbaros: juventud que irrumpe en una civilización para socavar sus bases. Junto con ésta, la metáfora del videoclip como forma de pensamiento.

\subsection{Culturas juveniles y ciberespacio}

Respecto de las investigaciones de la cultura en Internet, Ardèvol (2002) nos indica que las perspectivas se agrupan para definir la emergencia de nuevos modelos culturales cuyo eje vertebrador serían las tecnologías de la comunicación, pero que también hacen referencia al desarrollo de la inteligencia artificial y a la biotecnología, y se centran en el estudios de los aspectos culturales vinculados a la interacción social mediada por ordenador. Esto implica, necesariamente, tomar una posición -radical o intermedia- respecto de dos polos: si se considera que las formas culturales de Internet conforman otra cultura (la cibercultura), con interacciones diferentes a las que existen fuera de línea, o bien son parte de la evolución del modelo capitalista (Stratton: 1996) donde Internet es una tecnología más que tiene como consecuencia la disolución de las culturas locales para recomponerlas en un nuevo orden global. 
En el primer caso, se trata del estudio etnográfico de los estilos de vida juveniles online, en relación con uno de los aspectos de la noción de "cultura": el aprendizaje social y la vida en comunidad, cuyo referente más conocido en el área es Margaret Mead (escuela de Cultura y Personalidad de Estados Unidos). El punto más extremo de esta aproximación sería la afirmación de que la vida online no guarda relación con la vida offline o está liberada de los condicionamientos biológicos y socioculturales (Dery, 1994 en Ardevòl, 2002).

\subsubsection{Las ciberculturas juveniles}

El estudio sobre Ciberculturas presentado por Urresti (2008) tiene la singularidad de enfocarse en los jóvenes; el adjetivo juveniles es el modificador necesario para circunscribir el enfoque a los jóvenes como sujetos atravesados por la nuevas tecnologías, usuarios activos con subjetividades heterogéneas, y sobre la base de pensar a jóvenes que tienen acceso a los recursos ciberespaciales (sin entrar en las disquisiciones acerca de las diferencias entre lo digital, la CMC, los nuevos medios, la Web, el ciberespacio, etc.). Nuevamente, se interpretan los modos de ser joven según el parámetro de generación .

Su perspectiva integra la cuestión juvenil dentro de un contexto histórico específico, donde las vivencias generacionales tienen asidero en los espacios digitales y las prácticas en línea se alternan con los rituales y habitus cotidianos no digitales.

Pensar a los jóvenes en esta línea se vincula con las nociones de comunidad, sociedad,creencias, temporalidad, valores y permite preguntarse si se puede concebir la Red como sociedad, o si sólo Internet conforma la Cibercultura. Más aun si tomamos la idea de Cáceres (1998), que explica en qué consiste la representación imaginaria de la sociedad:

La sociedad también es el primer plano de lo imaginario. La gran pregunta es por la representación que de ella hacemos, y las relaciones que hay entre esa representación y las situaciones y las acciones en que intervenimos y con las cuales construimos desde lo inmediato a ese entorno mediato inmenso y supra individual que es lo social. Los actores sociales tienen una imagen de lo que son y el contexto en que se desenvuelven. [...] se podría decir que su mundo es del tamaño y de la complejidad de esa imagen, y lo social deriva de ella. (Cáceres, 1998, p.11) 
A esto podemos agregarle que las sociedades imaginan a sus grupos y construyen discursos a partir de imágenes sobre las juventudes.

Las investigaciones articuladas y orientadas al estudio de subjetividades juveniles (y aquí incluyo a los estudios sociológicos, psicológicos y discursivos) en el Ciberespacio pueden enmarcarse en contextos de la sociedad de la comunicación (op.cit, p.12), caracterizada por el autor como una estructura mixta en la que las formas horizontales de percepción espaciotemporal se subordinan a la estrucutura vertical pero la contrarrestan de algún modo, o bien de las comunidades de comunicación, donde las relaciones horizontales se imponen por sobre las verticales. Con todo, estas formas de uso en la apropiación de las herramientas y lenguajes virtuales, supone que se les atribuye significado social y simbólico.

\subsection{La cuestión generacional}

En un exhaustivo trabajo, Feixa (2006) describió una serie de categorías de clasificación de las juventudes por su pertenencia a una determinada generación, que sintetiza las diversas representaciones sobre los y las jóvenes en el siglo XX: Generación A (Adolescente), Generación B (Boy Scout), Generación K (Komsomol), Generación S (Swing), Generación E (Escéptica),Generación R (Rock’n'roll), Generación H (Hippy), VIII. Generación P (Punk), Generación T (Tribu) y Generación R (Red). Cada una de ellas representa, metafóricamente, una década, y se articula en torno del o los hechos sociales, políticos o culturales que nuclearon a los y las jóvenes tanto simbólicamente como en prácticas culturales y discursivas concretas. En este sentido, se advierte que en el criterio clasificatorio del autor subyace la idea de generación como grupo delimitado por compartir unas mismas condiciones de existencia (Mannheim, 1990) y también por su contemporaneidad cronológica.

Retomando la última de dichas categorías (Generación Red), otro de los puntos que quisiera destacar en el amplio terreno de las representaciones sociales sobre las juventudes es el de la homogeneización generacional que nombra, distingue e 
interpreta a los jóvenes en este siglo y en relación con sus formas de interacción social:

Mientras algunos ven a los "niños digitales" como nuestra gran esperanza para el futuro, otros se preocupan de que los nuevos medios sean parte de una ruptura generacional y de un giro peligroso de los estándares existentes para el conocimiento, la alfabetización y el compromiso cívico. (Ito et.al, 2008:p.ix, trad. propia)

Esta cita condensa los polos discursivos más extremos de la relación entre juventud/ciberespacio (o bien la era digital). La fascinación esperanzada frente al temor por los riesgos de muerte de los modos tradicionales de ser y estar en el mundo.

Las distintas maneras de hacerlo atienden tanto a las prácticas discursivas como a las constituciones identitarias, conformaciones culturales y también representaciones sociales. Lo que se destaca en este escenario es la matriz generacional como tópico y estructura desde donde se habla de los jóvenes.

Como sabemos, la perspectiva generacional toma como punto de referencia algún acontecimiento trascendente que transforma a los individuos y a sus relaciones grupales. En este caso, las innovaciones tecnológicas de fines del siglo XX impactan notoriamente en el desarrollo histórico-social y político del siglo XXI.

Tal como lo enuncian Mizuko et. al. (2008:pp.vii-ix), que los medios digitales han sido adoptados por poblaciones diversas y prácticas no institucionalizadas, incluidas las actividades juveniles de pares. Una generación crece en una era donde los medios digitales son parte de los supuestos estructurales sociales y culturales de aprendizaje, el juego y la comunicación social. Según estos investigadores, los sujetos están comprometidos en una exploración sin precedentes de lenguajes, juegos, interacción social, resolución de problemas y actividades autodirigidas que llevan a diferentes formas de aprendizaje. Esto se refleja en expresiones de identidad, que supone independencia, creatividad y capacidad de aprender, juzgar y pensar 
Lo mencionado conduce, entonces, a la conformación de creencias sociales que forman parte de los cimientos discursivos actuales, de las representaciones y prejuicios en todo lo relacionado con el universo de los usos juveniles en el Ciberespacio.

En esta línea, Herring (2008) sintetiza el sentido y representación de la idea de brecha digital:

Como otros tipos de brecha digital, la brecha generacional suele ser interpretada en el sentido de que la gente de un lado de la brecha - los jóvenestienen mayor acceso y una mayor habilidad para utilizar las tecnologías que los de la otra -los adultos -que tuvo la desgracia de nacer antes de la llegada de Internet. (Herring, 2008, p.7)

De este modo, se nombra a las generaciones en entornos online como generación D, generación @, Generación Net, nativos digitales, etc.

Generación Net: son tecnofílicos. Sienten una atracción a veces sin medida por todo lo relacionado con las nuevas tecnologías, por conocerlas, emplearlas, poseerlas. Los Nets perciben que con las tic es posible la satisfacción de sus necesidades de entretenimiento y diversión, comunicación, información e incluso de formación.

Generación I: los niños nacidos a fines de los 80 y los 90, considerados la primera generación donde Internet estuvo siempre presente (Herring, 2008:71). Caracterizados por su sociabilidad online, bajar contenidos de entretenimiento y consultar la Web con un una gama más amplia de propósitos que los adultos o los jóvenes de generaciones anteriores.

Generación Y: inmediatamente posterior a la generación X, a esta generación la conforman las personas nacidas a partir de 1980. En tecnología vivieron el boom de Internet, la transición del DOS al Windows, y jugaron desde el Atari hasta el Xbox 360 . Se cree que esta Generación es más optimista, abierta a temas polémicos y a familias no tradicionales. Según The Financial Times, a diferencia de las generaciones anteriores, la mayoría de estos jóvenes han nacido en un contexto sin 
guerras y más próspero y sin padecer la incertidumbre de las generaciones anteriores. Por ello se sienten más confiados, son más críticos con los mensajes de los medios y disponen de más dinero.

La Generación @: Según apunta Piscitelli (2005), esta clase de jóvenes pertenece a lo que Business Week en su nota de tapa MySpace.com ha denominado "la Generación @”, cuya peculiaridad, que los distingue de los adultos es, no la de usar las redes sociales, sino la de ser esas redes sociales, estructuradas en torno al eje identitario, pero on line . Esta generación estaría constituida por los nativos digitales que tienen veinte años.

La Generación Z: nacidos entre 1995 y 2005 son, según Maioli, investigador de la UADE, estrictamente nativos digitales y nacieron rodeados de tecnología. Son ansiosos, curiosos y esperan respuestas cada vez más rápidas en todos los ámbitos; indagan todo en Internet y no se sorprenden con la expansión de las redes.

\section{8.¿Nativos digitales?}

Los discursos sociales, especialmente los educativos y de los medios de comunicación, han adoptado para sus lecturas e intervención en la realidad social el concepto de nativos digitales, a partir de la conocida metáfora propuesta por Prensky (2001a), en referencia a los estudiantes norteamericanos:

Ellos han pasado toda su vida rodeados por y usando computadoras, videojuegos, reproductores digitales de música, videocámaras, teléfonos celulares, y todos los demás juguetes y herramientas de la era digital.

[...]¿Cómo deberíamos llamar a estos "nuevos" estudiantes de hoy? Algunos se refieren a ellos como la generación $\mathrm{N}$ [por Net] o generación D [por digital]. Pero la designación más útil que encontré para ellos es Nativos digitales. Nuestros estudiantes son todos hoy "hablantes nativos" del lenguaje digital de las computadoras, videojuegos y de la Internet (p.1)

En una segunda parte de su artículo, Prensky (2001b) confrontó su punto de vista sobre la dicotomía nativos/inmigrantes digitales a partir de una serie de evidencias 
estadísticas en investigaciones de tipo cognitivo. Posteriormente, en 2009, reelaboró sus conceptos, en torno a la noción representada en la imagen del homo sapiens digital, que refiere a la sabiduría de hombres y mujeres que aceptan la mejora digital de la existencia a la hora de acceder, mejorar y complementar sus capacidades con las herramientas tecnológicas. Todo ello sin que la brecha generacional inmigrante/nativo sea determinante. De cualquier modo, persiste en mantener la distinción original entre ambas categorías.

Piscitelli (2009, p.46) también adhiere a esta forma de representación generacional donde se destaca como variable de diferenciación la competencia comunicativa en uso del lenguaje digital- para referirse, utilizando términos semejantes a Prensky, a los estudiantes, preferentemente entre 5 y 15 años, "hablantes nativos del lenguaje de la televisión interactiva, las computadoras, los videojuegos e Internet".

Sin embargo, esta rotulación, en cierta medida determinista, viene sufriendo algunos cuestionamientos a partir de su contextualización en geografías distintas a las del Primer Mundo o a los sectores más vulnerables y, especialmente, al riesgo de interpretar en forma metonímica "estudiantes" por "todos los jóvenes nacidos en la era digital."

Por citar sólo una de las críticas, transcribo a Jenkins (2007), quien se centra en lo que no muestra, pero sí implica, la distinción entre nativos e inmigrantes digitales :

[...] Hablar de 'nativos digitales' también puede enmascarar el acceso a los diferentes grados y el confort con las tecnologías emergentes que experimentan los distintos jóvenes. Hablar de los nativos digitales puede dificultarnos el prestar atención a la brecha digital en términos de quién tiene acceso a diferentes plataformas técnicas y la brecha de participación en términos de quién tiene acceso aciertas habilidades y competencias o, para el caso, ciertas experiencias culturales y las identidades sociales. (Jenkins, 2007,s/p.)

Imaginamos, porque así se ha instalado en los discursos sociales, que todos los chicos y chicas nacidos en la era digital son ciudadanos, consumidores, usuarios y 
expertos en nuevas tecnologías, manejo de redes sociales y lenguajes ciberespaciales. Asimismo, a partir de esta representación, se generan otras imágenes donde los jóvenes aparecen como los causantes de las deformaciones expresivas, lingüísticas y comunicativas a partir de sus prácticas verbales y no verbales en el ciberespacio.

Ambas construcciones son falsas, o al menos están muy alejadas de lo que en realidad ocurre. Basta solamente indagar entre estudiantes universitarios acerca de sus costumbres respecto de las nuevas tecnologías, los nuevos medios y géneros para darnos cuenta que son pocos los que saben armar un blog, que apenas manejan algunas herramientas operativas de los programas informáticos; que, si bien tienen teléfonos celulares, hacen usos de algunas aplicaciones y que sus prácticas de escritura tienen más que ver con sus trayectos escolares que con la intervención de la pragmática del chat. Esto no significa que no hayan crecido en un "ambiente" en el que prevalece una lógica comunicacional digital.

Resulta interesante la propuesta que surge como variante a la de nativos/inmigrantes, construida por D. White (2011) en torno a la distinción no exculyente entre residents y visitors. Los jóvenes se integran a esta organización, más aún si la interactividad por la web forma parte de sus prácticas cotidianas. Esto los definiría como residentes del ciberespacio, de acuerdo con la propuesta de White, basada en la idea de que un residente es un sujeto para quien la web es crucial para facilitar la proyección de su identidad, de sus relaciones y de sus prácticas. Esto lo distingue del visitante, que hace un uso esporádico y utilitario de las herramientas y servicios online.

Por tanto, hablar de apropiación tecnológica también se vuelve una cuestión que no resiste las generalizaciones. Es cierto que las tendencias mundiales colocan a los/las jóvenes como motores de las revoluciones ciberespaciales, de la democratización de la palabra en red, etc. Sin embargo, las realidades nos muestran que sólo una porción de ellos/as usan las herramientas de los nuevos medios en sus múltiples posibilidades, más allá del posteo en las redes sociales, la conversación online y los juegos virtuales.

Los nuevos medios convergentes en el ciberespacio son mediadores culturales (Martín Barbero: 1987, en González: 2012) en la medida en que estén ligados con las prácticas cotidianas de los sujetos, en una especie de estructura incrustada en las 
prácticas sociales. En este contexto, los medios no deben concebirse como simples aparatos tecnológicos, sino como mediaciones que tienen percepciones más amplias.

\subsection{Categorías de análisis de la juventud en los medios de comunicación}

En el campo de los estudios de la comunicación de masas argentino, Saintout (2012) ha establecido tres categorías que reúnen, cada una de ellas, un modo de construir a los sujetos jóvenes en los medios. Si bien se trata de generalizaciones algo intuitivas o sustentadas más bien en un pensamiento de sentido común, son válidas para integrarse a otras formas de construcción y representación académica y confrontarlas con instrumentos de investigación más rigurosos. Estas representaciones son, en palabras de la autora:

Los jóvenes del éxito: son los jóvenes de la publicidad, de los programas de la tarde (...), que aparecen hablando en primera persona, esos que responden sin lugar a dudas a los modelos hegemónicos de belleza mundializados, cuyos problemas principales (...)son conflictos puramente subjetivizados, sin referencia a los entornos sociales o políticos.

Los jóvenes desinteresados: cotidianamente se presenta a los jóvenes como desinteresados, como perdidos. Se dice que nada les interesa, y esta "nada" claramente tiene que ver con la idea de que no les interesa nada de lo que les interesó a las generaciones anteriores.

Los jóvenes peligrosos: desde el discurso de la Seguridad Ciudadana se van construyendo relatos e imágenes en torno a la centralidad de unos jóvenes que, se dice, no tienen nada que perder y por lo tanto son incontrolablemente peligrosos para el resto de la sociedad.

Respecto de los métodos y herramientas desarrolladas por los Estudios del Discurso, que es un campo que llega más tardíamente al universo de los Estudios de Juventudes, considero que deben integrarse operativamente para establecer las 
relaciones entre los usos lingüísticos y los contextos de producción, así como los diferentes géneros de producción de discursos.

Desde esta perspectiva analítica, en el caso Tucumán pude constatar, en el lapso 2001-2004, que el discurso hegemónico de la prensa escrita reprodujo una serie de imágenes juveniles, en las que los jóvenes fueron objeto de discurso, ubicados en el imaginario según diferentes lugares sociales (Palazzo, 2010a):

- El cambio o la participación como sujetos activos, por una parte y por otra, la exclusión del sistema o bien los jóvenes como problema social. Entre ambas, se reconocen dos variantes: la construcción de la condición juvenil como futuro y su representación como sujetos desencantados o pasivos.

- Edad social: representados en una edad diferenciada de la adultez y de la niñez, a través de aspectos identitarios y de evolución biopsicológica.

- Producto histórico-social, clasificación que obedece a un discurso de valoración negativa de los que podríamos llamar "hijos de la crisis" (en referencia a las consecuencias de los sucesos sociales de diciembre de 2001 en Argentina, que tuvieron como consecuencia la renuncia del presidente Fernando de La Rúa).

- Estado de vida, a diferencia de la categoría anterior, remite a un discurso de evaluación positiva acerca de este particular estado espiritual y que supera los límites cronológicos.

De este modo, las distintas informaciones y opiniones acerca de los jóvenes tienen significado ideológico (Van Dijk, 2003) ya que responden a las preguntas sobre identidad, prácticas objetivos, valores y sobre su relación con los otros grupos, pero desde la construcción discursiva hegemónica.

En lo que respecta a mi investigación desde comienzos de este siglo, la operatividad del Análisis del Discurso como interdisciplina me permitió construir una suerte de rompecabezas sociodiscursivo cuyo campo de análisis fueron tanto los discursos de las ciencias sociales como los académicos y los de la gente común. Asimismo, entender las formas de producción de discurso juvenil en entornos digitales. Entre 
estos polos de producción sobre y producción desde los jóvenes, fui encontrándome con categorías legitimadas desde los espacios del saber, con juicios y creencias sociales solidificadas en los discursos sociales y periodísticos, con dicotomías generacionales atravesadas por la nostalgia o el desconcierto. También, con respuestas sociopolíticas de acción juvenil a las representaciones negativas sobre juventud, en el intento por revertir la creencia que imagina a la juventud perdida (en pasado, la que se recuerda con nostalgia, o en presente, la que está "perdida", sin rumbo, sin solución, dentro de la sociedad).

En determinado momento, busqué alguna herramienta que, sin ser definitiva o proponerse clausurada, atravesara estos espacios del decir que son, en última instancia, ideológicos. Por ello comencé a abonar un concepto, el de ciberdiscurso juvenil (Palazzo, 2010b) que me permite advertir ciertas regularidades pragmáticas, semánticas e ideológicas dentro de los comportamientos discursivos juveniles en los espacios digitales y que se abre a la posibilidad de las diferencias.

\section{DISCUSIÓN}

Ingresar en el universo de "lo joven" es una tarea que precisa del hilo de Ariadna. Son tantas las posibilidades de acercamiento para quienes investigamos en este campo, que estamos obligados a tomar decisiones, encontrar el camino que nos oriente en la selección del objeto de análisis, la problemática, las teorías y la ideología implicadas en todo el proceso.

En este trabajo sólo he recorrido una porción de este vastísimo territorio, con la pretensión de contribuir a la conformación de un mapa de representaciones y categorías de referencia a la temática.

Con sólo mencionar la palabra juventud se activa una red de asociaciones que remiten tanto a la memoria individual -la propia juventud-como al qué es ser joven, cómo son los jóvenes, qué se dice sobre la juventud, qué hacen los jóvenes, así como las relaciones de oposición generacional, por sólo mencionar algunas cuestiones. En cada una de ellas, seguramente, habrá determinadas representaciones y actitudes que, sometidas a un proceso de selección, repetición, tematización, etc., se materializaron en enunciados dentro de contextos particulares, que son los discursos. Estos procesos pueden ser más o menos intuitivos, pero en el caso de los medios masivos de comunicación, cumplen una función sociocultural importante porque se construyen desde lugares de poder. 
En la red de representaciones sociales sobre juventud encontramos las creencias, el conocimiento de sentido común y los discursos que reproducen o construyen las imágenes, interpretaciones, tipificaciones, etc., sobre jóvenes y juventudes. Estos hechos discursivos provienen de muy diversos contextos de producción (desde los más cotidianos hasta los medios hegemónicos), y también banalizan la representación social cuando el discurso académico se naturaliza en el discurso periodístico, por ejemplo. Es el caso del concepto de tribus urbanas o el mismo concepto de juventud e incluso la fijación de presupuestos culturalmente cristalizados como la juventud está perdida o la juventud es un divino tesoro.

Los Estudios sobre Juventudes muestran, en la praxis académica y especialmente en Latinoamérica, un comportamiento doble de expansión y profundización, y en este movimiento va generando categorías teóricas que se aplican a priori o bien surgen del propio objeto de investigación.

La tentación de enamorarnos de las etiquetas es también nuestro reto: recorrer el devenir teórico y analítico de representaciones académicas e institucionales y ponerlos en crisis, así como someterlos a nuestros contextos regionales y locales, en el terreno de las subjetividades y prácticas. Conocer la procedencia de las categorías y confrontar su operatividad, o bien, reformularlas, buscar sus variantes, para que el estudio de los procesos tenga sentido y se pueda intervenir en la investigación empírica así como en realidad social de forma positiva y constructiva.

\section{REFERENCIAS}

AAVV. (2014). Estudios sobre juventudes en Argentina III. De las construcciones discursivas sobre lo juvenil hacia los discursos de las y los jóvenes, R. Borobia(coord.). General Roca: Publifadecs.

Arce Cortés, T. (2008). "Subcultura, contracultura, tribus urbanas y culturas juveniles: ¿homogenización o diferenciación?". En Revista argentina de sociología, año $6 \mathrm{n}^{\circ} 11$.

Buckingham, D. et al. (2008). Youth, Identity, and Digital Media. Edited by David Buckingham. The John D.and Catherine T. MacArthur Foundation Series on Digital Media and Learning. Cambridge, MA: The MIT Press. 
Cáceres , J. G. (1998). Cibercultura, ciberciudad, cibersociedad hacia la construcción de mundos posibles en nuevas metáforas conceptuales. En Estudios sobre las Culturas Contemporáneas, IV, pp.9-23. Recuperado de http:/ / www.redalyc.org/articulo.oa?id=31600702 . Consultado el 10/11/2014

Chaves, M. (2009): Estudios sobre juventudes en Argentina 2007. La Plata, Universidad Nacional de La Plata: Red de Investigadoras/es en Juventudes Argentina. Recuperado de http://www.editorial.unlp.edu.ar/22_libros_digitales/chaves-OK.pdf. Consultado el 10/11/2014

Feixa, C. (2013). “Culturas juveniles en la era glocal”, en G.Palazzo y P.Gómez (coords.): Sujetos, miradas, prácticas y discursos. Segundo Encuentro sobre Juventud, Medios e Industrias Culturales [e-book], INSIL-ININCO- Facultad de Filosofía y Letras, UNT, pp- 231-246 (e-book). Consultado el 1 del 11 de 2014 en el URL http://www.insil.com.ar/adminis/up-load/upload/sujetos.pdf

Feixa, C. (2006). Generación XX. Teorías sobre la juventud en la era contemporánea, Revista Latinoamericana de Ciencias Sociales, Niñez y Juventud. Vol. 4, No. 2, 2006. Recuperado de http://biblioteca.clacso.edu.ar/Colombia/alianza-cindeumz/20131029044835/art.CarlesFeixa.pdf.Consultado el 10/11/ 2014

Feixa, C. (1998). De jóvenes, bandas y tribus. Antropología de la juventud. Barcelona: Ariel.

González Hernández, D. (2012). Medios de comunicación y la estructuración de audiencias masivas, Razón y palabra No 61, México. Recuperado de http://www.razonypalabra.org.mx/anteriores/n61/dgonzalez.html. Consultado el $1 / 10 / 2013$.

Griffin, C. (1993). Representations of youth. Cambridge, UK: Polity. 
Herring, Susan C. (2008). Questioning the Generational Divide: Technological Exoticism and Adult Constructions of Online Youth Identity. En Youth, Identity, and Digital Media. David Buckingham (ed.). The John D. and Catherine T. MacArthur Foundation Series on Digital Media and Learning. Cambridge, MA: The MIT Press, pp.71-92.

Jenkins, R. (5 de diciembre de 2007): Confessions of an Aca-Fan. The Official Weblog Of Henry Jenkins [mensaje en un blog] Recuperado de //henryjenkins.org/2007/12/reconsidering_digital_immigran.html Consultado el 10/11/2014.

Jenkins, R. (2000). Categorization: identity, social process and epistemology. Current Sociology. Julio 2000, vol. 48, núm.3, Sage Publications LTD, Londres,pp, pp.725.

Maffesoli, M. (1990). El tiempo de las tribus. El declive del individualismo en las sociedades de masas. Barcelona: Icaria.

Mannheim, K. (1990 [1927]). Le problème des générations. Paris : Nathan.

Marcia, J. (1980). Identity in Adolescence, en J. Adelson (ed.) Handbook of Adolescent Psychology, pp.159-187. New York: Wiley.

Martín Barbero, J. (2002). Tecnicidades, identidades, alteridades: des-ubicaciones y opacidades de la comunicación en el nuevo siglo. En Diálogos de la comunicación, pp.8-23. n.64

Mignolo, W. (1985). Dominios borrosos y dominios teóricos: ensayo de elucidación conceptual, Filología, año XXI, pp. 21-40. 
Palazzo, M.G. (2010a). La juventud en el discurso: representaciones sociales, prensa y chat. Serie Tesis. Tucumán: Facultad de Filosofía y Letras, UNT.

Palazzo, M.G. (2010b). Aspectos comunicativos del ciberdiscurso juvenil. Consideraciones teóricas.En Revista Argentina de Estudios de Juventud, 3 [revista virtual].Recuperado

de: http://www.perio.unlp.edu.ar/revistadejuventud?q=node/4. Consultado el 1 del 11 del 2014 en el URL

Pini, M. et al. (2012). Consumos culturales digitales: jóvenes argentinos de 13 a 18 años. Buenos Aires: Educ.ar S.E.; Ministerio de Educación de la Nación

Piscitelli, A. (2009). Nativos digitales. Dieta cognitiva, inteligencia colectiva y arquitecturas de la participación. Buenos Aires: Santillana.

Prensky, M. (2009). H. Sapiens Digital: From Digital Immigrants and Digital Natives to Digital Wisdom, Innovate, 5 [Revista virtual]. Consultado el 1 del 10 del 2014 en el URL http://www.innovateonline.info/pdf/vol5_issue3/H._Sapiens_Digital_From_Digital_Immigrants_and_Digital_Natives_to_Digital_Wisdom.pdf

Prensky, M. (2001a), Digital Natives, Digital Inmigrants, On the Horizon, NBC University Press, vol. 9, $\mathrm{n}^{\mathrm{o}}$ 5. Recuperado de: http://www.marcprensky.com/writing/Prensky $\% 20-$ \%20Digital\%20Natives, \%20Digital\%20Immigrants\%20-\%20Part1.pdf. Consultado el 15/ 10 / 2014.

Prensky, M. (2001b). Digital Natives, Digital Immigrants, Part II: Do They Really Think Differently?[version electrónica], From On the Horizon NCB University Press, 9. Recuperado de: http://www.marcprensky.com/writing/Prensky\%20- 
\%20Digital\%20Natives,\%20Digital\%20Immigrants\%20-\%20Part2.pdf. Consultado el 10/11/ 2014.

Raiter, A. (2003). Lenguaje y sentido común: las bases para la formación del discurso dominante. Buenos Aires : Biblos.

Reguillo Cruz, R. (2012). Culturas Juveniles. Formas Politicas del Desencanto. México: Siglo XXI.

Reguillo Cruz, R. (2011). Los jóvenes creen en el dios Hoy por sobre todas las cosas [Entrevista], Revista N, 26 de febrero de 2011. Recuperado de http://www.revistaenie.clarin.com/ideas/ejercito-desesperanzados-RossanaReguillo_0_434356570.html. Consultado el 20/11/2014.

Saintout, F. (2012). Los medios hablan de los jóvenes... y ellos responden., en M.Kriger (Comp) Juventudes en América Latina. Abordajes multidisciplinarios sobre identidades, culturas y politicas, del siglo XX al siglo XXI. Buenos Aires: CAICYT.

Van Dijk, T. (2003). Ideología y discurso. Barcelona: Ariel

White, D. \& A. Le Cornu (2011). Visitors and Residents: A new typology for online engagement. En First Monday 16 [Revista Digital] n.9 - 5 September 2011. Recuperado de: http://www.uic.edu/htbin/cgiwrap/bin/ojs/index.php/fm/article/viewArticle/3 $\underline{171 / 3049}$. Consultado el 10/ $08 / 2014$.

Zaffaroni, A. (coord.) (2012): Estudios sobre juventudes en Argentina II. Líneas prioritarias de investigación en el área jóvenes/juventud: la importancia del conocimiento situado. Salta: EUNSa-ReIJA. 


\section{AUTORA:}

María Gabriela Palazzo. Profesora en Letras (1998) y Doctora en Letras (2008), Facultad de Filosofía y Letras de la Universidad Nacional de Tucumán, Argentina. Investigadora Asistente del CONICET e investigadora categoría III del CIUNT. Profesora Adjunta en "Introducción a los Estudios Literarios" (Letras) y docente a cargo por extensión de la asignatura "Análisis del Discurso" de Ciencias de la Comunicación (UNT). Docente de posgrado en la FFyL de la UNT.

Integra el Instituto de Investigaciones Lingüísticas y Literarias Hispanoamericanas (INSIL-UNT) y del Instituto de Investigaciones sobre el lenguaje y la Cultura (INVELEC-CONICET).

Becaria Doctoral y Posdoctoral del Conicet. Su investigación está ubicada en la intersección de los Estudios de Juventudes, los Estudios del Discurso y los medios de comunicación. Publicó numerosos trabajos científicos en este campo, así como dentro del área de los estudios literarios. Es autora del libro La juventud en el discurso: representaciones sociales, prensa y chat. 